\title{
Community treatment orders: how ethical without experimental evidence?
}

\author{
T. Burns ${ }^{1 *}$ and J. Dawson ${ }^{2}$ \\ ${ }^{1}$ University of Oxford, Oxford, UK \\ ${ }^{2}$ University of Otago, New Zealand
}

\begin{abstract}
Compulsory community treatment orders are a feature of most advanced mental health systems without convincing experimental evidence of benefits. Is it ethical to continue without such evidence? This paper argues that the responsibility for ensuring it is collected lies as much with Parliament as with researchers.
\end{abstract}

Received 2 January 2009; Revised 16 January 2009; Accepted 20 January 2009; First published online 6 March 2009

Key words: Community treatment orders, mental health policy, psychosis, random controlled trials.

\section{A long gestation}

After lengthy controversy the Mental Health Act 2007 is now in force, providing for supervised community treatment orders (CTOs) in England and Wales from November 2008. But how will responsible clinicians (RCs) exercise their discretion under the new regime? There is considerable flexibility as the powers provided are permissive, not mandatory. The RC 'may' recall a CTO patient to hospital, for instance, if ' $(a)$ the patient requires medical treatment ...; and $(b)$ there would be a risk of harm ...', but return to hospital is not required, even if the test is met. Open-textured terms, like 'disorder of mind', and 'appropriate to receive medical treatment', which also require discretion to apply, define eligibility for involuntary out-patient care. Widely varying practices may therefore emerge.

The law reform debate has reflected international 'fault-lines' in the design of such schemes (Dawson, 2006). They were first proposed in the UK in 1988 by the Royal College of Psychiatrists whose subsequent proposal in 1993 (Royal College of Psychiatrists, 1993) was remarkably similar to that now enacted. Earlier opposition combined ethical and civil liberties concerns but more recent criticisms emphasise the absence of convincing experimental evidence for CTOs. Have these doubts been adequately answered?

\section{The controversy over 'forced medication'}

One criticism drew heavily on a persistent misunderstanding that antipsychotic medication would be

* Address for correspondence: Professor T. Burns, Department of Psychiatry, University of Oxford, Warneford Hospital, Oxford OX3 7JX, UK.

(Email: tom.burns@psych.ox.ac.uk) forcibly administered to resisting patients in their own homes. But no such power was ever proposed and its conferral would probably conflict with established human rights to privacy, dignity and personal security (Niveau \& Materi, 2007). The practice is explicitly prohibited by the new law. No such power is required, in any case, for clinicians to have the confidence to use the scheme. In highly deinstitutionalized Australasia, no such power is conferred. The Victorian CTO Guidelines provide, for instance, that: 'it is not acceptable to use force to impose treatment in any community setting... [nor] to use the presence of the others (especially the Police) to coerce a person to take treatment' (Department of Human Services, 2005). A similar position obtains in New South Wales and New Zealand (Dawson, 2006), but Australasian clinicians still make active use of their CTO regimes.

\section{Variation in rates of use of CTOs}

There are striking variations in rate of use across jurisdictions and this leads to criticism that their use is arbitrary and poorly linked to clinical need. Broadly speaking, rates are low in Canada, high in Australasia and mixed in the USA (Lawton-Smith, 2005). 'Outpatient commitment', in the USA, varies enormously from less than two per 100000 in New York, to 22 in North Carolina, where the most influential randomized controlled trial (RCT) was conducted (Swartz et al. 1999), to 26 in Nebraska, and even higher in Washington DC (Lawton-Smith, 2005). In Australasia, rates vary from 55 per 100000 for Victoria, 44 for New Zealand, 43 for Queensland, 37 for New South Wales, down to 10 in Western Australia. Many factors can produce these variations, however, including differences in legislation and in community services. 
Whether the new regime for England and Wales will attract the confidence of clinicians remains to be seen. The prior Supervised Discharge and Guardianship schemes were not widely employed (Pinfold et al. 2001) despite providing only marginally less extensive powers. Initial use of CTOs may therefore be modest, but Australasian and Scottish patterns suggest a significant increase is likely over time (Lawton-Smith, 2005).

\section{Limits of the research base}

A recent review concluded that there is no conclusive evidence that CTOs prevent hospitalization (Churchill et al. 2007). The authors considered the research often fell short of the standards of evidence-based medicine. However, the hierarchy of evidence conventionally used can mislead in evaluating complex community interventions that are sensitive to local care structures (Slade \& Priebe, 2001; Wright et al. 2004; Burns et al. 2007). While the RCT is accepted as the 'gold standard' it has its limitations and may distort the very processes investigated.

Other less rigorous research models have provided a fair understanding of CTOs - how they are applied, to whom, their acceptability, and broad outcomes. The Churchill report concludes: 'There is remarkable consistency in the characteristics of patients on CTOs across jurisdictions in very different cultural and geographic settings ... typically males, around 40 years of age, with a long history of mental illness, previous admissions, suffering from a schizophrenia-like or serious affective illness ...' (Churchill et al. 2007). This shows considerable convergence among clinicians as to the patients for whom CTOs should be used.

\section{Patients' and psychiatrists' perspectives of the New Zealand regime}

New Zealand research indicates that opposition to CTOs can be exaggerated (Gibbs et al. 2005), with many patients reporting they preferred it to other alternatives. Experienced patients may have a more realistic understanding of their options than some of the pressure groups speaking for them. They knew the choice was between a CTO and other interventions that also involved coercion, such as continued compulsory in-patient care. They valued increased control over their lives, experienced in the community, plus the security of professional support. Most considered it 'a stepping-stone' to a more stable life, although a minority remained adamantly opposed. The qualitative evidence suggests that the line between voluntary and involuntary treatment is frequently blurred under a CTO, with patients often exerting increasing control (Mullen et al. 2006).

Most New Zealand psychiatrists considered that CTOs consolidated mental health staff, accommodation providers and patients into an effective collaboration (Romans et al. 2004). CTOs were not considered a substitute for good community services but wholly dependent on them. A small minority of dissenting clinicians remained concerned about the impact on the long-term therapeutic alliance.

\section{The missing link - a convincing RCT}

The introduction of CTOs will significantly alter practice and the Australasian experience (with comparable services and training) provides some basis for predictions. A well-recognized group of patients, who have previously been placed on section 17 leave for a number of weeks, are likely to remain in future on CTOs for longer periods of time (months and possibly years). CTOs will lengthen compulsory treatment and this carries the undoubted cost (or 'side-effect') of increased deprivation of liberty. A proposed treatment with an unsure outcome but undeniable side-effects surely demands a careful trial (probably several careful trials) to establish if its benefits outweigh its sideeffects.

To date the only successfully conducted RCT (Swartz et al. 1999) found no clear advantage for CTOs. Secondary analyses indicated that the results may have been compromised by variations in both clinical care and in the use of the CTO. The authors suggest that if these were optimized CTOs may reduce relapse, but have not established this experimentally. Current experimental evidence finds that CTOs increase deprivation of liberty without demonstrated benefit. Neither clinical nor policy commitment to CTOs has been deterred by this one equivocal result; the most common response (Churchill et al. 2007) has been to call for further high-quality studies either to confirm or contradict these findings.

Getting such high-quality experimental evidence is not going to be easy. First, the North Carolina study is quite unrepeatable. Randomly assigning patients from compulsory care to voluntary status would usually be illegal because random release from compulsion is not authorized by the statutory scheme. Second, RCTs require 'experienced clinical equipoise' and the Australasian experience indicates that this may soon evaporate. Clinicians may rapidly become convinced of CTOs' necessity, despite the absence of experimental evidence, and feel they cannot collaborate in good conscience. An RCT may therefore only be feasible soon after the introduction of CTOs. Despite well-recognized problems with evaluating new and 
unfamiliar interventions of this kind (Coid, 1994), it is probably now or never.

Luckily the 2007 Mental Health Act makes it possible to conduct a lawful RCT of the new regime without randomly releasing any patient from compulsory care. It permits a research design of randomly assigning patients to section 17 leave or a CTO, and then comparing the progress of the two groups. Short-term compulsory supervision under section 17 leave has not been abolished, but CTOs may be used in practice for longer, permitting a comparison of the outcomes from shorter- versus longer-term compulsory outpatient care.

Given the current state of the evidence, RCs will often be genuinely uncertain whether to use the CTO or section 17 leave option. They would be in genuine clinical equipoise and random allocation of patients between the options would not transgress the law. Two clinically similar populations of patients who need out-patient compulsion should result and we should be able to study the consequences of their compulsion for significantly different lengths of time. The Oxford Community Treatment Order Evaluation Trial (OCTET) study is attempting this task.

\section{The role of legislators}

It would not be lawful to conduct a pure trial of compulsory versus voluntary out-patient care unless that was authorized by Parliament, which is not currently the case. Clinicians, patients, taxpayers and researchers should all be concerned about this. Is it sensible to pass legislation mandating far-reaching and expensive changes in health care without adequate provision to check the outcomes? Traditional American suspicion of 'Big Government' and opposition to unnecessary public expenditure has often led US legislatures to demand careful evaluations of new laws. The legislation authorizes an initial period of flexibility with the new law so evaluation can refine the details. The results of the evaluation are then fed back to the legislature for immediate refinement of the law rather than much later to a relatively powerless bureaucracy. This process was adopted in New York, for instance, when adopting its new outpatient commitment scheme, under Kendra's Law (New York State Office of Mental Health, 1994).

As legislation becomes increasingly detailed and intrusive its impacts are notoriously hard to predict. Mental health legislation (such as prison, sentencing, housing and welfare policies) alters complex behaviours and changes sensitive thresholds. It has enormous potential for unintended consequences. Careful evaluation should be embedded from the start in the legislation, not left as an afterthought to the imagination of academics.

\section{Acknowledgements}

None.

\section{Declaration of Interest}

None.

\section{References}

Burns T, Catty J, Dash M, Roberts C, Lockwood A Marshall M (2007). Use of intensive case management to reduce time in hospital in people with severe mental illness: systematic review and meta-regression. British Medical Journal 335, 336.

Churchill R, Owen G, Singh S, Hotopf M (2007). International Experiences of Using Community Treatment Orders. Institute of Psychiatry: London.

Coid J (1994). Failure in community care: psychiatry's dilemma. British Medical Journal 308, 805-806.

Dawson J (2006). Fault-lines in community treatment order legislation. International Journal of Law and Psychiatry 29, 482-494.

Department of Human Services (2005). Community Treatment Orders: Chief Psychiatrist's Guideline. Victorian Government: Melbourne (www.health. vic.gov.au/mentalhealth).

Gibbs A, Dawson J, Ansley C, Mullen R (2005). How patients in New Zealand view community treatment orders. Journal of Mental Health 14, 357-368.

Lawton-Smith S (2005). A Question of Numbers. The Potential Impact of Community-based Treatment Orders in England and Wales. King's Fund: London.

Mullen R, Dawson J, Gibbs A (2006). Dilemmas for clinicians in use of community treatment orders. International Journal of Law and Psychiatry 29, 535-550.

New York State Office of Mental Health (1994). New York Mental Hygiene Law (1994) chapter 560, section 9.61. In Kendra's Law : Final Report on the Status of Assisted Outpatient Treatment, Appendix 1 (www.omh.state. ny.us/omhweb/Kendra_web/finalreport/).

Niveau G, Materi J (2007). Psychiatric commitment: over 50 years of case law from the European Court of Human Rights. European Psychiatry 22, 59-67.

Pinfold V, Bindman J, Thornicroft G, Franklin D, Hatfield D (2001). Persuading the persuadable: evaluating compulsory treatment in England using supervised discharge orders. Social Psychiatry and Psychiatric Epidemiology 36, 260-266.

Romans S, Dawson J, Mullen R, Gibbs A (2004). How mental health clinicians view community treatment orders: a national New Zealand survey. Australian and New Zealand Journal of Psychiatry 38, 836-841.

Royal College of Psychiatrists (1993). Community Supervision Orders. Royal College of Psychiatrists: London. 
Slade M, Priebe S (2001). Are randomised controlled trials the only gold that glitters? British Journal of Psychiatry 179, 286-287.

Swartz MS, Swanson JW, Wagner HR, Burns BJ, Hiday VA, Borum R (1999). Can involuntary outpatient commitment reduce hospital recidivism? Findings from a randomized trial with severely mentally ill individuals. American Journal of Psychiatry 156, 1968-1975.

Wright C, Catty J, Watt H, Burns T (2004). A systematic review of home treatment services. Classification and sustainability. Social Psychiatry and Psychiatric Epidemiology 39, 789-796. 